\title{
Propostas para um projeto energético popular com soberania, distribuição da riqueza e controle popular: compromissos com o povo brasileiro na Política Energética Nacional (2014)
}

Plataforma Operária e Camponesa da Energia

\section{I - A POLÍTICA ENERGÉTICA NACIONAL}

É inegável que a energia é a locomotiva do desenvolvimento das forças produtivas. Sua importância estratégica, no atual modo de produção, está relacionada à produção de valor nos processos produtivos. No entanto, o capital a utiliza como forma de ampliar a capacidade de trabalho dos trabalhadores para aumentar o lucro, a reprodução e acumulação de capital.

Há concordância que a energia é necessária na geração da riqueza, que a cadeia produtiva de energia cria postos de trabalho e renda e potencializa o bem estar das pessoas.

Também é evidente que a produção de energia pressupõe fontes para a sua geração e que hoje, nas atuais relações sociais de produção, o petróleo é indispensável e os potenciais hidráulicos com as atuais tecnologias possuem "menor custo de produção" para produção de eletricidade. 
Os vários usos da energia, como bem de produção, bem de consumo e bem de serviços, impulsionados pela elevada capacidade produtiva dos trabalhadores, proporciona altíssimo grau de produtividade do trabalho na cadeia da energia. Estes são elementos indispensáveis para compreender a disputa pelo controle do petróleo e dos potenciais hidráulicos. Contudo, os poderes econômicos hegemônicos que disputam o controle destas cadeias produtivas ligadas à energia, ocultam para quê e para quem tem sido planejado.

As privatizações, da década de 90 , impuseram grandes perdas ao povo brasileiro. Serviços públicos, direitos historicamente conquistados pela luta da classe trabalhadora, foram repassados ao regime de propriedade privada e convertidos em mercadorias.

Empresas estatais estratégicas foram transferidas ao controle das corporações transnacionais, causando redução da soberania energética. As instituições políticas de planejamento e de regulação das leis que foram sendo capturadas e subordinadas para o atendimento dos interesses privados, tem consolidado a entrega de importantes reservas estratégicas de energia, o aumento da exploração sobre os trabalhadores, consumidores e populações atingidas e inviabilizado as empresas estatais restantes, enquanto empresas fundamentais de políticas de regulação social, ao conduzi-las a assumir o modo de operação empresarial de mercado.

A eficiência e a excelência construída ao longo dos anos nestas empresas estatais pelos seus trabalhadores foram sendo paulatinamente dilapidadas, resultado do conjunto das políticas neoliberais ali instituídas.

No setor elétrico, em especial, a indústria foi fracionada e transformada em vários segmentos de negócios, estes estão organizados e comandados sob o predomínio do sistema financeiro internacional, que associadas a regras institucionais têm viabilizado a criação de um conjunto de práticas financeiras especulativas.

A elevada rentabilidade assegurada às empresas e acionistas privados que atuam na cadeia de produção de eletricidade está ancorada, principalmente, nas normas determinadas pela Agência Nacional de 
Energia Elétrica (ANEEL). Esta instituição tem lançado sobre os ombros de toda a população brasileira o peso de ter que arcar com a tarifa de energia elétrica entre as mais caras do mundo, apesar de que, a cadeia de produção de eletricidade no Brasil - certamente - está entre as de menor custo de produção, mundialmente.

Este modelo transformou a eletricidade em sua principal mercadoria, onde 64 milhões de residências são obrigados a pagar tarifas elétricas a preços de commodlty, baseado na fonte de maior custo internacional, que atualmente é a geração térmica. Isto tem proporcionado lucros extraordinários às corporações e seus acionistas privados como mostram as elevadas somas financeiras distribuídas na forma de dividendos e de remessas de lucros.

$\mathrm{Na}$ estrutura institucional de organização da indústria de eletricidade, o mercado livre de energia (Ambiente de Contratação Livre) tem se consolidado como espaço fundamental para impedir qualquer política de governo no sentido de exercer o controle social nos preços da eletricidade. É uma das principais fontes de especulação sobre os consumidores brasileiros que compram energia elétrica das empresas distribuidoras no denominado Ambiente de Contratação Regulada e, também, um mecanismo que transfere enorme riqueza aos grandes conglomerados exportadores de produtos de eletro intensivos, principalmente nos períodos de elevada hidrologia.

Aos trabalhadores e trabalhadoras diretamente ligados à indústria de eletricidade, este modelo institucional vem impondo uma reestruturação do trabalho no interior das empresas com a expansão da precarização do trabalho, através do aumento da jornada e intensificação do ritmo de trabalho pelas metas estabelecidas, e pela forma de contratação com a redução e diminuição dos trabalhadores do quadro próprio das empresas, concomitante, ao aumento do número de trabalhadores terceirizados - estratégia das empresas para rebaixar os ganhos dos trabalhadores e trabaIhadoras. As condições e insegurança no trabalho e a elevação das taxas de exploração têm alcançados níveis alarmantes, Vitimando trabalhadores e trabalhadoras diariamente. 
Em relação aos atingidos pelas obras, o que se verifica é a intensificação da violação de direitos humanos. As populações atingidas até hoje não possuem um política nacional de garantia dos direitos e reparação das perdas. As atuais regras de compensação tem se mostrado fontes de lucros aos donos das obras. As compensações aos atingidos são monetarizadas nos custos de investimentos, referenciando os preços de venda da energia elétrica e as respectivas receitas dos empreendimentos, portanto, se as compensações forem evitadas os custos de investimentos reduzem e como as receitas não mudam, as taxas internas de retorno aumentam e tornam-se extraordinárias.

No petróleo, o plano de instaurar o modelo de mercado com a privatização total da indústria petroleira do país, verificado a partir dos anos de 1990, foi interrompido pela luta da classe trabalhadora. O passo inicial foi a luta para conquistar a autossuficiência na produção de petróleo. A persistência e ampliação dos investimentos estatais em tecnologia e pesquisa levou a descoberta em território brasileiro de uma das maiores reservas de petróleo dos últimos anos, o pré-sal, mérito em quem acreditou na capacidade do trabalho dos trabalhadores e no fortalecimento da empresa estatal Petrobrás.

A descoberta do pré-sal criou as condições políticas para um maior fortalecimento da Petrobrás e mudança na lei de petróleo. A adoção de um modelo de produção mais avançado no pré-sal, "modelo de partilha", o aumento das reservas da estatal e, principalmente, a exclusividade da operação da Petrobrás no pré-sal, sinalizam a possibilidade de construção de um futuro melhor para população brasileira.

É fundamental, no próximo período, a consolidação da soberania nacional sobre estes recursos estratégicos e a sua correta aplicação nas áreas de educação, saúde e demais áreas sociais como determina a lei de partilha.

Apesar do reconhecimento dos avanços, medidas de fortalecimento da maior empresa do país necessita avançar muito, a começar, revendo o modo empresarial privado de gerir a Petrobrás. 
Esse modo de gestão empresarial é uma grave ameaça à saúde e segurança dos trabalhadores e trabalhadoras, tendo causado diversos acidentes e mortes. Desde 1995, mais de 300 trabalhadores morreram no Sistema Petrobrás, sendo que destes, $80 \%$ eram trabalhadores terceirizados. O número de terceirizados na Petrobrás e quatro vezes maior que o número de trabalhadores efetivos da empresa, situação que eleva o número de acidentes visto a precarização das condições de trabalho. No setor elétrico a situação é semelhante.

Assim, o modelo de mercado que organiza a produção e a distribuição da energia tem se tornado um dos grandes obstáculos para o desenvolvimento do povo brasileiro, especialmente no atual período de grande crise da economia mundial, onde a disputa internacional sobre territórios de maior lucratividade se intensifica, a exemplo do que vem acontecendo sobre o pré-sal e o setor elétrico brasileiro.

As vitórias eleitorais do campo popular desde 2002 sinalizam e reivindicam a interrupção e superação desse modelo de mercado. As medidas políticas adotadas até o momento não foram suficientes para recuperar a soberania energética por completo e superar o modelo atual, em especial no setor elétrico nacional.

Nesse contexto, a PLATAFORMA OPERÁRIA E CAMPONESA DA ENERGIA entende que as cadeias de produção de energia de nosso país devem estar sob controle social com o objetivo de produzir e distribuir riquezas para o povo brasileiro.

\section{II - O CENÁRIO FUTURO}

A questão energética e tema central na disputa política mundial. É inegável que os principais conflitos mundiais na atualidade ocorrem em função da disputa pelo controle das principais reservas de energia, com destaque especial para o petróleo.

Os países e populações que concentram grandes reservas têm sido constantemente atacados pelas forças militares dos países do capitalismo central, especialmente pelos Estados Unidos, Inglaterra, França e Alemanha. 
Os países centrais são os maiores consumidores de energia, no entanto são altamente dependentes de importações. Os Estados Unidos, por exemplo, consomem 19 milhões de barris de petróleo por dia (20\% do consumo mundial) e produzem apenas $60 \%$, dependendo de grandes importações (algo como três vezes a produção total da Petrobrás). A estratégia destes países é controlar as reservas mundiais e as rotas de escoamento de energia.

Nos diversos países detentores de reservas energéticas importantes, o que se verifica é que, onde existe maior controle do Estado sobre estas riquezas e maior a possibilidade de distribuição desta renda através de programas sociais, como se verifica na Venezuela, Noruega e Equador.

No cenário internacional, as grandes corporações privadas buscam apropriar-se, de todas as formas, dos potenciais energéticos e das empresas estatais. Neste caso, o objetivo central é a apropriação privada, com reprodução e concentração de capital.

É inegável que no último período um conjunto de países procura se afastar da hegemonia estadunidense, construindo um processo de articulação que tem consolidado o que chamamos de BRICs (Brasil, Russia, India, China e África do Sul).

Neste quadro de disputa internacional o Brasil, articulado iunto aos BRICs, nos governos Lula e Dilma adotaram uma série de medidas que fortalece a participação do Estado na economia, retoma o processo de planejamento e investimento no setor energético, junto de outras medidas econômicas e sociais que consolidaram o país como referência no cenário internacional.

Aliado a estes fatores, a descoberta do pré-sal coloca o Brasil numa situação de maior evidência mundial, configurando-se como uma potência em reserva energética. Esta situação possibilita a elaboração de uma nova lei, como a Lei de Partilha, tendo a Petrobrás como operadora única do pré-sal, incentivando ainda mais a produção industrial brasileira, através da política de conteúdo local, para atender a crescente necessidade das demandas da indústria do petróleo no Brasil. 
Junto com o crescimento da indústria do petróleo, o governo adotou outra medida importante no setor elétrico nacional. Aproveitando o momento de renovação das concessões de energia elétrica, o governo federal além de manter a concessão nas mãos das empresas estatais, reduziu os preços, sinalizando para um maior controle do Estado.

As medidas adotadas no petróleo e energia elétrica, Vão posicionando o rumo atual do país em direção que não coincide totalmente com os interesses econômicos e políticos dos Estados Unidos e das grandes corporações de petróleo e de energia elétrica.

A estratégia do imperialismo e seus aliados internos, e retomar as condições para uma futura privatização da Petrobrás e a entrega do pré-sal às empresas estadunidenses e europeias, para isso farão de tudo para interromper que o país construa maior soberania sobre a energia.

As forças reacionárias atuarão para retroceder e impedir a consolidação da lei de partilha e do Fundo Soberano, recursos que poderão resolver grande parte dos problemas de educação e saúde do povo brasileiro.

O esforço realizado na renovação das concessões do setor elétrico nacional, que iniciou um processo mais intenso do governo no controle e redução das tarifas, se transformou no principal foco de ataque dos agentes especuladores do setor elétrico para reposicionar as tarifas aos patamares mais elevados. Com seus ataques, os setores neoliberais reivindicam a liberalização total dos preços de energia elétrica (e combustíveis) para manutenção de taxas extraordinárias de lucratividade.

Os trabalhadores da energia, também têm sido foco de intensos ataques pelo capital que fará de tudo para rebaixar os ganhos da categoria para os níveis mais baixos. Assim também é o cenário dos direitos das populações atingidas e dos investimentos sociais e ambientais decorrentes das obras.

No cenário de crise mundial do capitalismo, o capital movimenta e atua para retomar o controle total sobre as instituições de Estado com representações políticas de sua extrema confiança. 
É em meio a este cenário de grande disputa política e seus desdobramentos que os trabalhadores e trabalhadoras do campo e da cidade terão que atuar para defender o projeto energético popular e derrotar os planos do capital.

\section{III - PROPOSTA POPULAR PARA A POLÍTICA ENERGÉTICA NACIONAL}

A proposta de projeto popular para energia entende que o problema central é a política energética, o modelo energético.

Estamos propondo superar o debate restrito de matriz. Para a PLATAFORMA a questão energética não se restringe ao debate sobre as fontes e as tecnologias de produção de energia, apesar de reconhecer a sua importância. O entendimento da Plataforma é de que o ato de planejar, organizar, controlar a produção e distribuição da energia e da riqueza gerada, bem como, o controle das reservas estratégicas que são base natural para elevada produtividade do trabalho, são atos no campo da política.

Defendemos as seguintes propostas populares para a política energética nacional:

1. Avançar na transformação e construção de instâncias institucionais no Estado Brasileiro para a ampliação da democracia, participação e controle popular nas decisões sobre a política energética nacional

a) Criar espaços institucionais de participação dos trabaIhadores e das trabalhadoras na política energética nacional, em especial, no planejamento e na organização da produção e distribuição da riqueza produzida nas cadeias de produção de energia reestruturando as instituições políticas de Estado existentes, como exemplos: o Conselho Nacional de Política Energética (CNPE); a Empresa de Pesquisa Energética (EPE), as Agências afins, Empresas, entre outras. 
b) Fomentar e promover ações institucionais, com a garantia da participação popular, visando estabelecer amplo debate nacional com o povo brasileiro para tomada de decisões sobre as grandes questões energéticas do país, através de mecanismos de plebiscito popular, referendo popular, conferências populares, audiências públicas adequadas, seminários, programas, entre outros.

\section{Realizar mudanças políticas e institucionais para superar o modelo energético de mercado}

a) Ampliar o controle do Estado sobre os preços da energia na busca pela redução das tarifas de energia elétrica, levando em consideração o custo de produção real do sistema, e dos combustíveis, em especial o gás de cozinha e diesel, seja através de mecanismos legais e/ ou administrativos.

b) Que a totalidade da contratação de energia seja através do ambiente de contratação regulado, levando em consideração o custo de produção real do sistema elétrico brasileiro e o acesso à energia como direito humano fundamental.

c) Realizar mudanças nas atuais instituições políticas de Estado e leis (a começar pelas agências reguladoras) que organizam, regulam e reproduzem as cadeias industriais energéticas com o objetivo de superar o modelo de mercado e garantir e atender os interesses dos trabalhadores e trabalhadoras. Em especial, nas agências reguladoras, garantindo um modelo público de regulação, com mecanismos de participação e decisão popular institucionalizada em todos processos sobre os serviços públicos.

d) Fim do ambiente de contratação livre, a começar pelo fim da atual política do PLD (preço de liquidação das diferenças), porque o Ambiente de Contratação Livre e a política atual do PLD são os principais mecanismos de especulação sobre os consumidores cativos (residenciais principalmente), 
atuam como instrumentos para impedir a redução das tarifas e meio de transferência de riqueza para os grandes conglomerados internacionais exportadores de produtos de alta densidade energética.

e) Rever a atual política de "preço-teto" que determina e garante o preço da eletricidade como commodity, concomitantemente, encaminhar o debate para implementar uma política de preço para os energéticos fundamentada na metodologia do custo do serviço".

f) Garantia de $100 \%$ de contratação da energia elétrica para as distribuidoras.

g) Fim das "comercializadoras" de energia elétrica, instrumentos da especulação que atuam como paraísos fiscais, e retomada ao controle total do Estado.

h) O ONS (Operador Nacional do Sistema) sob controle total do Estado, pelo seu caráter estratégico e importância nacional, deve ser transformado numa empresa pública.

\section{Fortalecer as empresas estatais}

a) Participação maior do Estado no controle das estatais e da energia: política de fortalecimento e participação cada vez maior do Estado no controle das estatais e das reservas energéticas, como instrumento principal para o desenvolvimento da indústria de petróleo e eletricidade, com adequada prestação de contas ao povo brasileiro.

b) Construir o monopólio estatal sobre o petróleo e gás por meio de uma Petrobrás $100 \%$ pública, conforme PLS $531 / 2009$ e, o fim das concessões de energia. Enquanto se avança para esse objetivo maior, consolidar o modelo de partilha, como principal modelo de produção a ser adotado, garantindo a Petrobrás como operadora única no pré-sal 
e que os excedentes das atividades tenham destinação social para resolver os grandes problemas do povo brasileiro.

c) A Petrobrás, Eletrobras e demais estatais sem venda de capital, privatização ou fatiamento. Estas empresas estatais, de caráter público, devem ser indutoras do desenvolvimento com soberania nacional para superar as desigualdades regionais, valorizar o trabalho, manter e ampliar o conhecimento acumulado.

d) Fortalecer as empresas do sistema Eletrobras como principal empresa de desenvolvimento da política energética nacional no setor elétrico e fortalecer as distribuidoras estatais não privatizadas.

e) Estatização das usinas hidrelétricas com concessões vencendo garantindo $100 \%$ controle estatal, com a preservação (e ampliação) integral dos ganhos decorrentes das instalações amortizadas ao povo brasileiro, bem como, dos postos de trabalho aos trabalhadores.

f) Participação majoritária das empresas estatais nos consórcios de energia. 